Macklin explores the failures of ethical review committees in clinical research settings in developing countries. Despite a thorough review of the ways in which Western guidelines can fail patients, her evident support for the principles of the American model, in which a "more robust" system monitors the activities of institutional review boards (IRBs), hints dangerously at political imperialism. The proliferation of the procedures of such review boards can easily result in crippling overregulation. Collaborative studies conducted by federally funded institutions are a good example of this. A simple minimal risk village study (e.g., an examination of stool for the prevalence of parasites) conducted over a five-year period could require 40 separate IRB approvals (or renewals) - at great expense of money, time and effort. The fact that the multiplicity and redundancy of ethical reviews serves only to slow developments and thereby delay public health improvements is an issue that Macklin does not address.

Although we applaud Macklin's efforts to lobby on behalf of vulnerable populations of developing countries, we'd like to emphasize that ethical double standards are not confined to developing countries. There are 41 million Americans without health insurance and, according to Families USA (a national nonprofit, nonpartisan organization dedicated to the achievement of highquality affordable health care for all Americans), 65 million without prescription drug coverage. Although Macklin condemns the paternalistic paradigm often adopted by IRB committees in industrialized countries for medical research in developing countries, in her text she often supports the American medical system as a model. As in developing countries, subjects of drug trials conducted in the United States do not have access to all effective diagnostics and treatments once the trial is over. Access is limited by poverty in the United States as much as in any other country.

The grossly unequal provision of health care in the United States seems to escape Macklin's criticism. This blindside is something of a double stan- dard in itself. Given the lack of an ideal bioethical model in any Western nation, in any conflict between local IRBs and those of the sponsor's country the former should take precedence. This would better protect research subjects in vulnerable populations and also check the neocolonial approach adopted by many American IRBs.

Readers working in medical research in developing countries will inevitably find Macklin's frequent references to the following documents helpful: the Declaration of Helsinki (original and revised versions); the International Ethical Guidelines for Biomedical Research Involving Human Subjects, published by the Council for International Organizations for Medical Sciences; guidelines provided by the National Bioethics Advisory Commission; and UNAIDS documents. Macklin often quotes from these sources to highlight contradictions in the opinions by officials holding positions of influence within national and international agencies, such as the World Health Organization and the US Food and Drug Administration.

As we aspire to balance medical progress, public health and patient rights with the interests of industrialized countries, developing countries and pharmaceutical companies, we encounter a myriad of dilemmas. Whether one agrees or disagrees with Macklin's viewpoint, Double Standards in Medical Research in Developing Countries is a thoughtprovoking summation of the most troubling bioethical issues in clinical research trials and is, on balance, a worthy addition to the Law, Medicine and Ethics series of the Cambridge University Press.

\section{Kate Turner}

Asociación Benéfica PRISMA

Lima, Peru

Robert H. Gilman

Bloomberg School of Public Health

Johns Hopkins University

Baltimore, Md.

\title{
Looking out a window at St. Michael's Hospital
}

The cars outside scurry into parking holes:

an attendant administers tickets and takes money.

His gate goes up. Traffic breeds thick on the street.

Using paper bags for pillows, derelicts sleep in the square.

Townhouse roofs are worn from too much rain,

too much sun. An argument over money: Pay me then

and No, you stole it! A few joggers trot. Squads

of kids dispense their tortures. One pamphleteer

installs himself outside the hospital entrance

and is ignored. Sirens sound their Doppler calls;

pigeons swoop down on litter falling from pedestrians'

hands. A man wanders along the sidewalk; he looks lost.

This squat window is open, a perfect portal: no expanse, just a small demesne, a city as broad as its enclosure.

I turn around, a man lies with the sheets drawn

to his neck; only the damaged godhead is visible. A face

$\approx$ that loomed in life recedes each day, too gaunt

for arguments. I turn away. Outside, fewer cars pass.

The parking lot empties. Vagrants stir. Half a moon

presides over grief as patch of cityscape.

\section{Shane Neilson}

Family Physician

Guelph, Ont. 